University of Wollongong

Research Online

$1-1-2017$

\title{
A diet enriched with red sorghum flaked biscuits, compared to a diet containing white wheat flaked biscuits, does not enhance the effectiveness of an energy-restricted meal plan in overweight and mildly obese adults
}

\author{
Anita Stefoska-Needham \\ University of Wollongong, an442@uowmail.edu.au \\ Eleanor J. Beck \\ University of Wollongong, eleanor@uow.edu.au \\ Stuart K. Johnson \\ Curtin University \\ Marijka Batterham \\ University of Wollongong, marijka@uow.edu.au \\ Ross Grant \\ University of New South Wales, University of Sydney
}

See next page for additional authors

Follow this and additional works at: https://ro.uow.edu.au/ihmri

Part of the Medicine and Health Sciences Commons

\section{Recommended Citation}

Stefoska-Needham, Anita; Beck, Eleanor J.; Johnson, Stuart K.; Batterham, Marijka; Grant, Ross; Ashton, John F.; and Tapsell, Linda C., "A diet enriched with red sorghum flaked biscuits, compared to a diet containing white wheat flaked biscuits, does not enhance the effectiveness of an energy-restricted meal plan in overweight and mildly obese adults" (2017). Illawarra Health and Medical Research Institute. 1018. https://ro.uow.edu.au/ihmri/1018 


\title{
A diet enriched with red sorghum flaked biscuits, compared to a diet containing white wheat flaked biscuits, does not enhance the effectiveness of an energy- restricted meal plan in overweight and mildly obese adults
}

\begin{abstract}
Objectives: Whole grain sorghum is a promising ingredient in foods, especially those targeting satiety and weight control. This study aimed to test weight loss effects of a whole grain red sorghum product incorporated into an energy-restricted diet.

Methods: Sixty subjects (46 females) were randomized to either a sorghum (intervention) or white wheat (control) group, receiving $45 \mathrm{~g}$ of flaked cereal biscuits to include daily in their prescribed diets for 12 weeks. Primary outcome was weight loss. Secondary outcomes included plasma glucose, glycosylated hemoglobin ( $\mathrm{HbA1c}$ ), insulin, total cholesterol, high-density lipoprotein cholesterol (HDL-c), low-density lipoprotein cholesterol (LDL-c), triacylglycerides (TAG), interleukin (IL)-1 $\beta$, IL-6, IL-8, tumor necrosis factor alpha (TNF- $\alpha$ ), high-sensitivity C-reactive protein (hs-CRP), and total antioxidant capacity (TAC; measured at 0 and 12 weeks).

Results: After 12 weeks, there were no significant differences in weight loss or any clinical variables between a wheat control and sorghum cereal group in an energy-restricted diet. Equivalent amounts of weight were lost $(p=0.369)$ in both groups, and the majority of clinical indices such as fasting glucose, insulin, cholesterol, and key inflammatory biomarkers showed significant beneficial changes over time ( $p$ $<0.05)$.
\end{abstract}

Conclusions: Although both groups experienced significant weight loss and general improvement in a number of clinical measures, no effects appeared specifically related to sorghum consumption. Further clinical trials are necessary to establish an evidence base for weight loss effects from chronic sorghum intake. Sorghum represents a viable, gluten-free grain alternative in the formulation of novel food products.

\section{Keywords}

does, wheat, white, containing, compared, biscuits, flaked, sorghum, red, enriched, diet, mildly, overweight, plan, meal, adults, energy-restricted, obese, effectiveness, enhance, not

\section{Disciplines}

Medicine and Health Sciences

\section{Publication Details}

Stefoska-Needham, A., Beck, E. J., Johnson, S. K., Batterham, M. J., Grant, R., Ashton, J. \& Tapsell, L. C. (2017). A diet enriched with red sorghum flaked biscuits, compared to a diet containing white wheat flaked biscuits, does not enhance the effectiveness of an energy-restricted meal plan in overweight and mildly obese adults. Journal of the American College of Nutrition, 36 (3), 184-192.

\section{Authors}

Anita Stefoska-Needham, Eleanor J. Beck, Stuart K. Johnson, Marijka Batterham, Ross Grant, John F. Ashton, and Linda C. Tapsell 


\title{
Original Research
}

\section{A diet enriched with red sorghum flaked biscuits, compared to a diet containing white wheat flaked biscuits, does not enhance the effectiveness of an energy-restricted meal plan in overweight and mildly obese adults}

\author{
Authors: Anita Stefoska-Needham ${ }^{1}$ (MSc), Eleanor J. Beck ${ }^{1}(\mathrm{PhD})$, Stuart K. \\ Johnson $^{2}(\mathrm{PhD})$, Marijka J. Batterham ${ }^{3}(\mathrm{PhD})$, Ross Grant ${ }^{4}(\mathrm{PhD})$, John Ashton ${ }^{5}$ \\ $(\mathrm{PhD})$, Linda C. Tapsell ${ }^{1}(\mathrm{PhD})$. \\ ${ }^{1}$ School of Medicine, Illawarra Health \& Medical Research Institute, University of Wollongong, \\ NSW, 2522, Australia. \\ ${ }^{2}$ School of Public Health, Faculty of Health Sciences, Curtin University, Perth, WA, 6845, Australia \\ ${ }^{3}$ Statistical Consulting Centre, National Institute for Applied Statistics Research Australia, University \\ of Wollongong, NSW, 2522, Australia. \\ ${ }^{4}$ School of Medical Sciences, University of NSW, Sydney, NSW, 2052, Australia; \\ Sydney Adventist Hospital Clinical School, University of Sydney, Sydney, NSW, 2006, Australia. \\ ${ }^{5}$ Sanitarium Development and Innovation, Cooranbong, NSW, 2265, Australia.
}

\section{Corresponding author (including reprint requests):}

Anita Stefoska-Needham

School of Medicine, Illawarra Health \& Medical Research Institute, University of

Wollongong, Wollongong, 2522 Australia.

T: +61 458850088; an442@uowmail.edu.au

\section{Funding and conflict of interest disclosures:}

This project was supported by The Australian Research Council in the form of a Linkage Project grant (LP10020012) and a collaboration agreement between the University of Wollongong (UOW) and the Australian Health and Nutrition Association. Authors declare no conflict of interest.

\section{Running title:}

Effects of a sorghum-enriched diet in humans

Key words:

Sorghum, Whole grain sorghum, Health, Weight management, Satiety, Flaked cereal biscuit

\section{Abbreviations:}

HbA1c, Glycosylated hemoglobin; TC, Total cholesterol; HDL-C, High density lipoprotein cholesterol; LDL-C, Low density lipoprotein cholesterol; TAG, Triacylglycerides; IL1 $\beta$, Interleukin 1 $\beta$; IL-6, Interleukin 6; IL-8, Interleukin 8; TNF $\alpha$, Tumor necrosis factor alpha; hsCRP, High sensitivity c-reactive peptide; TAC,

Total antioxidant capacity 


\begin{abstract}
Objectives: Whole grain sorghum is a promising ingredient in foods, especially those targeting satiety and weight control. This study aimed to test weight loss effects of a whole grain red sorghum product incorporated into an energyrestricted diet.

Methods: Sixty subjects (46 females) were randomized to either a sorghum (intervention) or white wheat (control) group, receiving $45 \mathrm{~g}$ of flaked cereal biscuits to include daily in their prescribed diets for 12 weeks. Primary outcome was weightloss. Secondary outcomes included plasma glucose, HbA1c, insulin, total cholesterol, HDL-C, LDL-C, TAG, IL1 $\beta$, IL-6, IL-8, TNF $\alpha$, hsCRP, TAC (measured at 0 and 12 weeks).
\end{abstract}

Results: After 12 weeks, there were no significant differences in weight loss or any clinical variables between a wheat control and sorghum cereal group in an energy-restricted diet. Equivalent amounts of weight were lost $(\mathrm{p}=0 \cdot 369)$ in both groups and the majority of clinical indices such as fasting glucose, insulin, cholesterol and key inflammatory biomarkers showed significant beneficial changes over time $(\mathrm{p}<0.05)$

Conclusions: Although both groups experienced significant weight loss and general improvement in a number of clinical measures, no effects appeared specifically related to sorghum consumption. Further clinical trials are necessary to establish an evidence base for weight loss effects from chronic sorghum intake. Sorghum represents a viable, gluten-free grain alternative in the formulation of novel food products. 


\section{INTRODUCTION}

Dietary patterns rich in plant foods are positively associated with indicators of health [1].

These diets include a variety of foods and food components that have beneficial effects on disease markers and health outcomes, including body weight regulation, important in the prevention of chronic disease [2]. Characteristically high in dietary fiber, phytonutrients and lower in total energy value, the purported benefits of these diets may be attributed to mechanisms involving satiety and appetite regulation, glycemic and insulinemic control, lipid regulation, and reduced oxidative stress and inflammatory processes.

Whole grain cereal foods constitute an important component of plant-based diets. They are a source of dietary fiber and contain an array of bioactive compounds, including polyphenols. Sorghum (Sorghum bicolor L. Moench) is an example of a gluten-free whole grain cereal, with a reputation for being satiating [3]. Not surprisingly, sorghum is gaining attention from food manufacturers and researchers as a suitable ingredient in foods targeting satiety to assist with longer-term weight management, particularly in populations where obesity-related diseases are prevalent and food is ubiquitous [4]. Sorghum's appeal is further enhanced by its potential as a sustainable crop with numerous agronomic advantages including low production costs, high temperature tolerance and adaptability to drought $[5,6]$.

Sorghum grain is mostly composed of starch, with levels reported as high as $71 \%$ of dry whole grain weight in some cultivars [7]. Sorghum starch granules are entangled in a strong protein matrix in the corneous endosperm (hard outer region) of the grain kernel, which may impede the actions of carbohydrate-hydrolyzing enzymes, resulting in reduced in vitro starch digestibility [8]. The starch granules exist in a more open structure in the floury endosperm of the grain kernel. More commonly utilized hard wheat is also characterized by a higher ratio of 
corneous to floury endosperm, in which the starch granules are more tightly bound to proteins. The lower starch digestibility may also be a consequence of interactions with the cell wall material and polyphenolic compounds such as flavonoids (namely anthocyanins) and condensed tannins $[9,10]$. A variety of sorghum-based foods have been confirmed to deliver slowly digestible starches (SDS) [11, 12], which have been associated with lower glucose responses, and in some cases lower glycemic index (GI) [13]. Together with dietary and resistant starch, this array of qualities may result in enhanced satiety through which sorghum grain components may play a role in longer-term weight management and protection against obesity-related chronic diseases [5]. To date, indications for such effects have predominantly come from in-vitro $[11,13]$ and animal studies $[14,15]$. Our group has previously conducted the only clinical trial investigating satiety mechanisms relating to sorghum grain consumption in humans [16]. Using a crossover design in 20 male and 20 females subjects, three different types of sorghum flaked whole grain cereal biscuits (made from red, white or brown grained sorghum varieties and differing in polyphenolic content) were shown to extend acute subjective satiety sensations and increase satiety-enhancing gut hormones (GLP-1 and GIP and PYY in males) to a greater extent than a wheat control over a 4-hour period $(\mathrm{p}<0.05)$, although food intake at a second meal was not altered. The flaked biscuits made from red sorghum grain, a variety rich in anthocyanin flavonoids, elicited the greatest overall satiety-enhancing responses. We were unable to explain the responses in terms of the dietary fiber or the starch contents of the biscuits, but overall differences in polyphenol contents may have assisted the satiety responses.

While these initial acute satiety results were promising, longer-term effects on body weight and chronic disease biomarkers are the main target for providing evidence of health benefits. The present paper describes a 3-month randomized controlled dietary intervention trial, 
designed to test effects of whole grain red sorghum included in an energy-restricted meal plan. The primary outcome was weight loss. Secondary outcomes were biochemical measures linked with change in body weight, such as glucose, insulin, cholesterol and a number of antiinflammatory/oxidative stress markers, as well as subjective satiety measures. We hypothesized that (1) subjects receiving foods made from whole grain sorghum would lose more weight than subjects receiving control foods (wheat-based); (2) weight loss would be accompanied by changes in metabolic disease risk factors, which may be anticipated given the high polyphenolic content of the sorghum.

\section{METHODS AND MATERIALS}

\section{Subjects and recruitment}

This study was a 3-month, double-blinded, parallel, randomized controlled trial with a total of 60 subjects, 46 females and 14 males. There were two arms to the study: sorghum intervention and wheat control, with both groups receiving advice on an energy-restricted diet from an Accredited Practising Dietitian. All subjects were provided with cereal products, in the form of flaked breakfast biscuits, to include in their diets. The target sample size of 30 subjects per group was based on previous human intervention studies incorporating cereal/high fiber foods into hypo-caloric diets [17-19]. Difference in weight loss between groups was used as the primary outcome measure to establish power for the study. To observe a two-kilogram weight difference between groups, at a power of $80 \%$ and to be significantly different at level of $\alpha 0.05,26$ subjects would be required per group. Therefore, setting the recruitment target at 30 subjects per group would account for an approximate dropout rate of 15\%. Eligible subjects (aged $18-65$ years, BMI range from $25-35 \mathrm{~kg} / \mathrm{m}^{2}$ ) were sought through paid media advertisements and institutional emails. Subjects with serious illness including diabetes, with known food allergies, and those taking appetite-altering medications 
were excluded from the study. Restrictive eaters (identified using the Three Factor Eating Questionnaire by Stunkard \& Messick [20]) and subjects who were smokers, were pregnant, breastfeeding and post-menopausal were also excluded. All procedures were approved by the University of Wollongong, Human Research Ethics Committee (approval number HE14/100). The trial was also prospectively registered with the Australian New Zealand Clinical Trials Registry (ACTRN12614000640606).

A total of 115 potential subjects expressed interest in the study of which 103 were contacted to undergo further preliminary screening via telephone (Figure 1). From this group, 80 people were eligible for further assessment in the form of a detailed screening questionnaire. This led to sixty-one people attending an interview to determine final eligibility with sixty subjects randomized into the two study groups by a researcher independent of the subject interface, stratified by sex, block randomized using STATA Version 12 and using the RALLOC command (StataCorp, 2011, College Station, Texas, USA). The researcher/dietitian and all subjects at the subject interface were blinded to the randomization. The subjects attended the clinical research trials unit (CRTU) at the University of Wollongong, Australia, on five occasions. The first visit included collection of background dietary data using a validated diet history interview [21] and instruction on the completion of a 3-day weighed food record. The subsequent visit included collection of fasting blood samples (baseline) and dietary education. Two follow-up dietary visits occurred at the 1-month and 2-month time-points, with collection of fasting blood samples at 3 months (final visit). All the subjects had their height, weight, percentage body fat (Tanita Scales Model no.TBF-662) and waist circumference recorded at each visit to the CRTU. Visual analogue scales (VAS) related to appetite [22] and food records were all completed at baseline, half-way through the study (at the 6-week point) and within the final week of the study. The Baecke Physical Activity Questionnaire [23] was 
completed at baseline and at the completion of the study.

For the appetite VAS, the subjects recorded their appetite responses on individual forms at six different time- points throughout the day: immediately before each of the three main meals and $2 \mathrm{~h}$ after each of these meals but before their subsequent snack. The VAS consisted of a $100 \mathrm{~mm}$ horizontal line, anchored at each end with opposing responses (for example, "not at all hungry" and "never been more hungry"). The study participants were instructed to place a vertical mark on the line to correspond with their feelings and the subjective sensation was quantified by measuring the distance in millimeters from the left end of the line to the mark. All nutritional analysis was performed using FoodWorks 2007, version 5 (Xyris Software, Brisbane, QLD, Australia) with nutrient contents of study foods added as required.

\section{Dietary intervention}

For each subject, a basal metabolic energy requirement was calculated using the Mifflin-St Jeor equation where a BMI equal to $25 \mathrm{~kg} / \mathrm{m}^{2}$ was included [24]. A low activity factor (1.3) was chosen to estimate energy requirements (given the overweight sample with limited usual physical activity) and then this level was reduced by $20 \%$ to drive weight loss. Intervention diets were designed to control for all macronutrients with the only variation being the trial cereal products given, as described in Table 1. The sorghum intervention group received whole grain sorghum-based cereal biscuits and the whole wheat control group received wheat-based cereal biscuits, matched by serve size ( 3 biscuits) and therefore overall mass (45g per day). Wheat was chosen as the suitable food control because it has a different polyphenolic profile to red sorghum but has similar nutritional attributes and, from a behavioral perspective, wheat cereal products are readily interchangeable with sorghum breakfast cereal products. 


\section{Test food products}

Organoleptically-acceptable test foods were manufactured in the form of ready-to-eat (RTE) flaked cereal biscuits, in a pilot processing plant by qualified cereal food technologists, as previously described by Stefoska-Needham et al. (2016). The sorghum flaked cereal biscuits were processed from red sorghum grain, variety Alpha, grown and supplied by Lochabar Enterprises Pty Ltd (Tara, QLD, Australia), with a small amount of added malt extract. A bleach test [25] confirmed the absence of tannins in the red sorghum grain. The wheat flaked cereal biscuits were made from non-cultivar-specific Australian Prime White (APW) hard wheat (grown in central New South Wales, Australia) and was supplied by Sanitarium Health and Wellbeing (Cooranbong, NSW, Australia). The whole wheat and whole sorghum grains were steamed and then passed between parallel smooth rollers producing whole grain flakes, reducing their thickness to $0.1 \mathrm{~mm}$. The flakes were pressed together to form rectangular prism-shaped biscuits, which were subsequently toasted in an oven to reduce the moisture content and produce a shelf stable product [16]. This process differs from the shredded wheat process in that the wheat is not cut into strips at any stage.

The subjects were instructed to eat two cereal biscuits (30g) at breakfast and one biscuit $(15 \mathrm{~g})$ at afternoon tea daily. The proximate, dietary fiber and energy content (on as is basis per 100g) (Table 2), polyphenolic (PP) content (mg GAE/g as is) (Table 3) and starch properties (per 100g as is) (Table 4) were previously reported by Stefoska-Needham et al., 2016). Analyses identified modest differences between the control and sorghum biscuits with respect to energy, macronutrients and dietary fiber (Table 2). Notably, both total and soluble fiber levels were higher in the whole wheat control compared to the sorghum biscuits, however the actual difference between biscuits was modest at $0.86 \mathrm{~g}$ and $0.13 \mathrm{~g}$ per $45 \mathrm{~g}$ test serve, 
respectively. Individual macronutrient levels were not controlled for because this study was designed to test whole foods as consumed in real-life settings, hence the serve size rather than specific components were matched. As expected, red sorghum biscuits had higher PP levels compared to the control (Table 3), most likely due to high anthocyanin contents characteristic of this sorghum variety [3]. Assessment of starch properties showed no difference in the amount of total starch, rapidly digestible starch (RDS) and slowly SDS between biscuits, and in particular the levels of SDS in each serve classified as high (Table 4).

\section{Clinical indices}

Fasting blood samples were collected at 0 and 3 months into clot gel tubes, centrifuged and stored at $-80^{\circ}$ Celsius until analysis could be completed according to standard protocols for glucose, insulin, total cholesterol, high-density lipoprotein (HDL-c), low-density lipoprotein (LDL-c), triacylglycerides (TAG) and high-sensitivity c-reactive peptide (hsCRP) at Sydney Adventist Hospital Pathology (Wahroonga, NSW, Australia). Glycosylated hemoglobin (HbA1c) was performed by Southern Pathology (Wollongong, NSW, Australia) after samples were collected into tubes containing potassium EDTA and stored at $4^{\circ}$ Celsius until analysis was conducted. Additional markers for inflammation and oxidative stress, Interleukin $1 \beta$ (IL1 $\beta$ ), Interleukin 6 (IL-6), Interleukin 8 (IL-8), tumor necrosis factor alpha (TNF $\alpha$ ) and total antioxidant capacity (TAC) were performed by the Australasian Research Institute, (Sydney Adventist Hospital, Wahroonga, NSW, Australia) according to established protocols.

\section{Statistical analysis}

Data for all anthropometry, blood analysis, VAS measurements and dietary intake were entered into SPSS for windows, version 21.0 (IBM SPSS 21.0, IBM Corporation, Armonk, NY, USA). Repeated measures ANOVA (RMANOVA) using the general linear model with 
group (control, sorghum) as the between subjects factor, was used to identify primary changes in each parameter over time and also differences between the groups. Post hoc analysis using Bonferroni adjustments was reviewed to detect specific differences between the control and intervention groups. Regression analysis was used to identify correlations between group anthropometric and biochemical indices.

\section{RESULTS}

\section{Baseline data}

There were twenty-six subjects in the sorghum intervention group (after four subjects withdrew) and thirty subjects in the control group (Figure 1). Reasons provided for their withdrawal were: relocation, commencement of a contraindicated medication and the lack of motivation to adhere to an energy-restricted meal plan. For the final analysis, fifty-six subjects were included, although numbers in each calculation varied because some subjects did not complete all forms (food records or VAS). There were no significant differences between group anthropometric, dietary and metabolic measures at baseline (Table 5), except for a slightly lower protein intake in the sorghum group. Baseline energy intakes seemed low, suggesting under-reporting by some subjects. Consequently at subsequent study visits, dietitians specifically addressed potential under-reporting with subjects when reviewing their individual food records. The subjects were mildly obese but overall they did not exhibit impaired glucose tolerance or insulin resistance [26], nor were they hyperlipidemic [27] or hypertensive [28].

\section{Dietary intervention}

The flaked cereal biscuits were consumed by subjects with no adverse reactions and dietary compliance was relatively high at approximately $85 \%$, as determined by a manual count of 
uneaten biscuits upon study completion. Food record analysis indicated no significant difference between the groups for protein, carbohydrate and fat intakes at any of the timepoints once the study commenced. Review of the overall dietary composition of baseline diets compared with the 3-month end-point showed a significant decrease in percentage energy from fat $(\mathrm{p}<0.001)$, as well as saturated fat $(\mathrm{p}<0.001)$. Percentage energy from protein and carbohydrate was not altered over time (Table 6).

Compliance with a weight reduction meal plan was identified by overall weight loss and energy reduction reported in the food records. Total energy intake was significantly lower at the mid-point (mean 7136 (SD 2164) kJ) and the end-point (mean 6880 (SD 1815) kJ) $(\mathrm{p}<0.001)$ of the trial compared with the baseline (mean 8742 (SD 2656) kJ), using RMANOVA with treatment as the between-group effect and time as the within-subject variant. The lack of an interaction effect over time $(\mathrm{p}=0.671)$ suggests that there were no differences between groups in energy intake over time. There were no significant differences in activity scores between the groups at any time-point, indicating that changes in physical activity were not a factor in influencing overall results.

\section{Clinical indices}

The majority of the anthropometric and biochemical indices changed over 3-months; however, there were no significant differences between the groups for any of the measured clinical parameters over this time (Table 7). The average weight loss for the study sample was significant at $5.3 \mathrm{~kg}(\mathrm{p}<0 \cdot 001)$ (or $6.1 \%$ of baseline body weight) over the 3 -month intervention. The mean weight changes ranged from a $2.1 \mathrm{~kg}$ gain to a $14.7 \mathrm{~kg}$ loss, however weight loss was not significantly different between the groups $(\mathrm{p}=0 \cdot 369)$. Waist measurements and percentage body fat decreased significantly compared to baseline 
$(\mathrm{p}<0.001)$. Regression analysis indicated that weight loss significantly predicted waist change $(\mathrm{p}<0 \cdot 001)$ and percentage body fat $(\mathrm{p}<0 \cdot 001)$. As expected, these predictions were strong $\left(R^{2}\right.$ 0.389 and $R^{2}$ 0.615). Fasting blood glucose $(\mathrm{p}<0 \cdot 001)$ and fasting insulin levels decreased over 3 months $(\mathrm{p}<0.001)$ but HbA1c did not change. No between groups differences were identified for any of these clinical indices (Table 7). The inflammatory cytokines IL1 $\beta$, Il-6 and Il-8, decreased significantly compared to baseline ( $\mathrm{p}<0.001)$, as did TNF $\alpha(\mathrm{p}<0 \cdot 001)$. TAC levels also decreased significantly compared to baseline $(\mathrm{p}<0.001)$. There were no significant changes over time in hsCRP levels. The reduction in total cholesterol was not significantly different between the groups, with mean decreases of 0.3 (SD 0.6) mmol/l for the sorghum group and 0.5 (SD 0.7) $\mathrm{mmol} / \mathrm{l}$ for the control. There was a significant decrease in total cholesterol over 3 months for all subjects ( $p<0.001$ ), as well as significant decreases in HDL-c $(\mathrm{p}<0.001)$, LDL-c $(\mathrm{p}<0.05)$ and TAG $(\mathrm{p}<0.001)$ levels over this time.

\section{Subjective satiety}

VAS results were reviewed for the six daily time-points at 0,6 and 12 weeks to compare any differences that may have existed between the control and test groups (RMANOVA). No significant differences were identified, demonstrating that all individuals reported similar feelings of hunger/fullness at the same test points (data not shown).

\section{DISCUSSION}

As a consequence of the dietary intervention, a reduction in energy intake was achieved in the overweight study sample. The reduced energy intake in both groups was an effective driver of weight loss over the 3-month period. Regardless of the diet subjects followed, they lost weight and experienced beneficial changes in waist circumference, fasting glucose, fasting insulin, lipids and inflammatory markers. If maintained over time, the mean weight loss of 
$6.1 \%$ and reduced waist circumference $(10.9(\mathrm{SD} 5.4) \mathrm{cm})$ for the study sample, could decrease risk of insulin resistance, impaired glucose tolerance and dyslipidemias [29], as well as lower the incidence of developing type 2 diabetes [30].

The present study was not able to confirm differentiating effects of sorghum grain consumption on weight loss in an energy-restricted diet over 12 weeks where only the test foods were different. This design is necessary, however, for rigorous testing of individual foods where other dietary confounders are cancelled out. Despite a previous acute satiety study with promising results [16], the present study showed that differences in meal satiety do not necessarily translate to weight reduction differences in the longer term. Bearing in mind that the energy restriction of the total diet was the same for both groups, subjects receiving foods made from sorghum included in the dietary advice, did not lose more weight than the subjects receiving control foods and similar overall dietary advice. Thus, the mealbased satiety-enhancing mechanisms postulated to involve sorghum polyphenols did not have an enhancing effect on body weight changes over 3 months, nor on overall reduction in metabolic disease risk factors. Previous research conducted by our group has also shown that where both the control and intervention diets focus on healthy eating patterns and control for energy intakes, a difference in weight loss is not seen [31]. Ostensibly this is because weight loss is dependent on control of energy intake and we matched the percentage energy reduction in both arms. Typically also, no differences are seen when structured dietary advice to both the control and intervention groups is provided [32], as was the case in the present study. However, differences in other risk factor variables (affected by dietary attributes other than total energy, such as dietary fat $[33,34]$ have been observed. Given our assumption that a higher polyphenol intake from sorghum may have had similar effects, the study design was 
appropriate, but we may now need to look to other potential synergistic components of the diet, or a higher dose to pursue our hypothesis further.

The lack of differences between groups in changes in lipid levels was not consistent with another study investigating the effects of consuming sorghum foods on serum lipid levels [35]. In this study, a significant reduction $(\mathrm{p}<0.05)$ in total cholesterol, TAG and HDL-c was observed in 10 males and 6 females after daily consumption of $100 \mathrm{~g}$ of unrefined sorghum in the form of pancakes over 3 weeks. However, this study used a small sample size (with low statistical power), reducing the likelihood that a statistically significant result reflects a true effect. Further, the content of subjects' background diets was not adequately reported, making assessment of dietary confounders and final conclusions difficult. Overall, these results are ambiguous hence more human evidence for lipid effects in relation to sorghum consumption is warranted, and may be more relevant where weight loss inducing diets are not prescribed so as to discern lipid lowering effects independent of weight loss.

A further strength of the present study was that we addressed the polyphenolic composition of the test foods. From a physiological perspective, we considered the results of a recent randomized, controlled, crossover human study, involving 22 healthy adults, assessing the acute effects of consuming pasta containing red or white wholegrain sorghum flour $(30 \%$ sorghum, 70\% semolina) on plasma total polyphenols, TAC and oxidative stress markers compared to a wheat control made from $100 \%$ semolina [36]. Pasta containing red wholegrain sorghum flour (RSP), but not white sorghum flour, enhanced antioxidant status and improved markers of oxidative stress in healthy subjects $(\mathrm{p}<0.001)$. The increase in plasma polyphenols by the RSP meal was attributed to its higher content of polyphenols. In the present study, despite significant differences in the levels of polyphenols and TAC between the test food 
products, we were not able to detect differences in the levels of inflammatory biomarkers and plasma TAC between the sorghum intervention and wheat control groups (Table 3). The reasons are not clear as to why the TAC levels unexpectedly decreased over time even though the inflammatory markers showed significant improvement. While standard protocols were followed and precautions taken, possible oxidation of blood samples during preparation or storage, cannot be ruled out [37]. Furthermore it may be that the effects of ingesting sorghum grain components are short-lived and subtle, hence the positive outcomes observed in acute studies may not translate to whole of diet studies conducted over a number of months.

The lack of differences in subjective satiety scores was perhaps expected. VAS are validated for use in highly controlled situations [22], such as acute meal test studies. We justified the inclusion of VAS to enable a possible link between reported ratings in this study and those of our previous acute satiety study [16], though realistically, the small differences from month to month in the present study were unlikely to be captured accurately by the subjects using the VAS tool. An alternative appetite questionnaire, validated for use in free-living conditions [38], may have been more informative.

Separating out the effects of individual components within a food, in this case the flaked cereal biscuit matrix, is difficult within a human intervention trial. To this end, a key strength of the present study is the comprehensive characterization of the physico-chemical properties of the test foods used in the intervention diets, assisting researchers to link clinical effects to components within the food. In our previous work [16], determination of polyphenolic compounds, dietary fiber, profiling of starch contents and proximate analyses of the RTE sorghum flaked biscuits, enabled us to hypothesize that the polyphenolic compounds played a role in observed acute satiety effects that would drive weight loss in the present RCT. Overall, 
the lack of positive results should not infer that sorghum is not a beneficial ingredient in cereal foods, as subjects consumed the foods successfully, lost weight, decreased their serum cholesterol and showed other positive outcomes related to metabolic health. The whole grain sorghum product was as effective as the whole grain wheat product in the present study. Sorghum, like other whole grain cereals, delivers beneficial, health-promoting components and properties (such as antioxidants, dietary fiber, SDS and valuable energy) when it is consumed as part of a healthy food within a healthy diet.

As with most human dietary intervention trials, there are a number of confounding variables in the present study that require some consideration. Firstly, the trial was only a 3-month intervention and this period of time may not be long enough to detect differences between the subjects' compliance with an energy restricted diet and the actual effects of the dietary intervention. It has been shown that subjects who reported greater compliance with a weight loss protocol lost more weight regardless of the dietary intervention [39], suggesting that strategies to increase adherence may be more important than the actual composition of the diet. Validated "measures of adherence" to enhance compliance to dietary advice in the context of clinical interventions would therefore be useful in future studies [40].

Secondly, the present study included similar test food products for both the intervention group and the control group, which only varied in the source of whole grain (sorghum versus wheat). The effect of individual grain components within the cereal biscuits, even if positive, are likely to be relatively small and hence showing a statistical difference between the groups would be difficult, especially over 3 months. Significant differences between the treatment and control groups may have been detected if the whole wheat control biscuits were lower in dietary fiber and higher in RDS compared to the sorghum biscuits. Further, instructing 
subjects to eat food products at both breakfast and at afternoon tea as part of the compliance criteria for the dietary intervention protocols, may have actually increased overall energy consumption at times when the subjects might otherwise have chosen not to eat or to eat less in either arm of the study.

Thirdly, it is difficult to control the dietary intake of human subjects. Although food records and discussions with subjects during study interviews indicated high compliance with consumption of test products, the subjects were less compliant with the energy restriction as evidenced by the lower-than-predicted weight loss. All four subjects that withdrew from the study were from the intervention group, which could infer the greatest difficulty with compliance, but this is less likely given the reasons provided for their withdrawal. Lastly, large standard deviations existed within all the analyzed datasets, limiting the ability to detect significant results. The large standard deviations indicated that individual fluctuations are more varied than any overall effect of sorghum intake.

\section{CONCLUSION}

Although both groups experienced significant weight loss and general improvement in all clinical measures such as fasting glucose, insulin, cholesterol and key inflammatory biomarkers, no effects appeared specifically related to sorghum consumption. Overall, there were no discernable differences between an energy-restricted diet containing a wheat-based cereal food and that containing a sorghum-based cereal food. With a longer intervention and greater exposure to the test foods, some differences might have been detected, as subtle effects of components in the cereal foods would become more prominent. Nevertheless, the consumption of sorghum flaked breakfast cereal biscuits in the context of an energy-restricted diet is not deleterious in overweight and mildly obese individuals, and in fact represents a 
viable gluten-free alternative to wheat in food products.

\section{ACKNOWLEDGEMENTS}

We are grateful to the management and staff of the Illawarra Health \& Medical Research Institute for the opportunity to conduct this study in their clinical trials unit and for their assistance with collection of blood samples. Thank you also to Monique de Abreu, Kayla Thornhill, Emma Goddard, Ryan Platt and Kurt Morton (University of Wollongong dietetics students) for assistance with data entry. A heart-felt thank you to all the study participants for their time and commitment to this important research.

\section{AUTHORSHIP}

$A S-N, E J B, J A, R G$ and LCT designed the study. AS-N conducted the study, analyzed dietary and biochemical data, and performed statistical analyses (guided by MJB). Biscuits were formulated by the industry sponsor, led by $J A$. AS- $N$ wrote the first draft of the manuscript and all authors read, edited, and approved the final manuscript. AS-N had primary responsibility for the final content. 


\section{REFERENCES}

[1] National Health and Medical Research Council: Dietary Guidelines of Australia.

NHMRC, Canberra, Australia, 2013.

[2] Slavin JL, Green H: Dietary fibre and satiety. Nutr Bull 32:32-42, 2007.

[3] Awika JM, Rooney LW: Sorghum phytochemicals and their potential impact on human health. Phytochem 65:1199-1221, 2004.

[4] Stefoska-Needham A, Beck EJ, Tapsell L.C: Perspective: The path to confirming and exploiting potential satiety-enhancing effects of sorghum-based foods for human diets. Qual Assur Saf Crop DOI:10.3920/QAS2015.0695, 2016.

[5] Stefoska-Needham A, Beck EJ, Johnson SK, Tapsell LC: Sorghum: An Underutilized Cereal Whole Grain with the Potential to Assist in the Prevention of Chronic Disease. Food Rev Int 31:401-37, 2015.

[6] Taylor JRN, Schober TJ, Bean SR: Novel food and non-food uses for sorghum and millets. J Cereal Sci 44:252-71, 2006.

[7] Serna-Saldivar S, Rooney LW: Structure and chemistry of sorghum and millets. In: Dendy DAV (ed): "Sorghum and Millets Chemistry and Technology." St Paul, MN: American Association of Cereal Chemists, pp 69-124, 1995.

[8] Duodu KG, Taylor JRN, Belton PS, Hamaker BR: Factors affecting sorghum protein digestibility. J Cereal Sci 38:117-31, 2003. 
[9] Barros F, Awika JM, Rooney LW: Interaction of tannins and other sorghum phenolic compounds with starch and effects on in vitro starch digestibility. J Agric Food Chem 60:11609-17, 2012.

[10] Daiber KH: Enzyme inhibition by polyphenols of sorghum grain malt: J Sci Food Agric 26:1399-1411, 1975.

[11] Licata R, Chu J, Wang S, Coorey R, James A, Zhao Y, Johnson, SK: Determination of formulation and processing factors affecting slowly digestible starch, protein digestibility and antioxidant capacity of extruded sorghum-maize composite flour. Int J Food Sci Technol 49:1408-19, 2014.

[12] Yousif A, Nhepera D, Johnson S.K: Influence of sorghum flour addition on flat bread in vitro starch digestibility, antioxidant capacity and consumer acceptability. Food Chem $134: 880-87,2012$.

[13] Lemlioglu-Austin D, Turner ND, McDonough CM, Rooney LW: Effects of sorghum [Sorghum bicolor (L.) Moench] crude extracts on starch digestibility, Estimated Glycemic Index (EGI), and Resistant Starch (RS) contents of porridges. Molecules 17:11124-38, 2012.

[14] Cervantes-Pahm SK, Liu Y, Stein HH: Comparative digestibility of energy and nutrients and fermentability of dietary fiber in eight cereal grains fed to pigs. J Sci Food Agric 94:841$49,2014$. 
[15] Shen R-L, Zhang W-L, Dong J-L, Ren G-X, Chen M: Sorghum resistant starch reduces adiposity in high-fat diet-induced overweight and obese rats via mechanisms involving adipokines and intestinal flora. Food Agric Immunol 26:120-30, 2015.

[16] Stefoska-Needham A, Beck EJ, Johnson SK, Chu J, Tapsell LC: Flaked sorghum biscuits increase post-prandial GLP-1 and GIP levels and extend subjective satiety in healthy subjects. Mol Nutr Food Res 60:1118-28, 2016.

[17] Katcher HI, Legro RS, Kunselman AR, Gillies PJ, Demers LM, Bagshaw DM, KrisEtherton PM: The effects of a whole grain-enriched hypocaloric diet on cardiovascular disease risk factors in men and women with metabolic syndrome. Am J Clin Nutr 87:79-90, 2008.

[18] Hu X, Gao J, Zhang Q, Fu Y, Li K, Zhu S, Li D: Soy fiber improves weight loss and lipid profile in overweight and obese adults: a randomized controlled trial. Mol Nutr Food Res 57:2147-54, 2013.

[19] Ross AB, Godin JP, Minehira K, Kirwan JP: Increasing whole grain intake as part of prevention and treatment of nonalcoholic fatty liver disease. Int J Endocrinol 2013:585876, 2013.

[20] Stunkard AJ, Messick S: The three-factor eating questionnaire to measure dietary restraint, disinhibition and hunger. J Psychosom Res 29:71-83, 1985. 
[21] Martin GS, Tapsell LC, Denmeade S, Batterham MJ: Relative validity of a diet history interview in an intervention trial manipulating dietary fat in the management of Type II diabetes mellitus. Prev Med 36:420-28, 2003.

[22] Flint A, Raben A, Blundell JE, Astrup A: Reproducibility, power and validity of visual analogue scales in assessment of appetite sensations in single test meal studies. Int J Obes $24: 38-48,2000$.

[23] Baecke JAH, Burema J, Frijters JER: A short questionnaire for the measurement of habitual physical activity in epidemiological studies. Am J Clin Nutr 36:936-42, 1982.

[24] Mifflin MD, St Jeor ST, Hill LA, Scott BJ, Daugherty SA, Koh YO: A new predictive equation for resting energy expenditure in healthy individuals. Am J Clin Nutr 51:241-247, 1990.

[25] Waniska R, Hugo L, Rooney LW: Practical methods to determine the presence of tannins in sorghum. J Appl Poultry Res 1: 122-128, 1992.

[26] National Health and Medical Research Council: National evidence based guidelines for case detection and diagnosis of type 2 diabetes. NHMRC, Canberra, Australia, 2009.

[27] Tonkin A, Barter P, Best J, Boyden A, Furler J, Hossack K, Sullivan D, Thompson P, Vale M, Cooper C, Robinson M, Clune E: National Heart Foundation of Australia and the Cardiac Society of Australia and New Zealand: position statement on lipid management2005. Heart Lung Circ 14:275-91, 2005. 
[28] Chobanian AV, Bakris GL, Black HR, Cushman WC, Green LA, Izzo JL: The seventh report of the joint national committee on prevention, detection, evaluation, and treatment of high blood pressure: The JNC 7 report. JAMA 289:2560-71, 2003.

[29] Singh GK, Siahpush M, Hiatt RA, Timsina LR: Dramatic increases in obesity and overweight prevalence and body mass index among ethnic-immigrant and social class groups in the United States, 1976-2008. J Commun Health 36:94-110, 2011.

[30] Hamman RF, Wing RR, Edelstein SL, Lachin JM, Bray GA, Delahanty L, Hoskin M, Kriska AM, Mayer-Davis EJ, Pi-Sunyer X, Regensteiner J, Venditti B, Wylie-Rosett J: Effect of weight loss with lifestyle intervention on risk of diabetes. Diab Care 29:2102-07, 2006.

[31] Tapsell LC, Dunning A, Warensjo E, Lyons-Wall P, Dehlsen K: Effects of Vegetable Consumption on Weight Loss: a review of the evidence with implications for design of randomised controlled trials. Crit Rev Food Sci Nutr 52:1529-38, 2011.

[32] Beck EJ, Tapsell LC, Batterham MJ, Tosh SM, Huang XF: Oat beta-glucan supplementation does not enhance the effectiveness of an energy-restricted diet in overweight women. Brit J Nutr 103:1212-22, 2010.

[33] Tapsell LC, Batterham MJ, Teuss G, Tan SY, Dalton S, Quick CJ, Gillen LJ, Charlton KE: Long-term effects of increased dietary polyunsaturated fat from walnuts on metabolic parameters in type II diabetes. Eur J Clin Nutr 63:1008-15, 2009. 
[34] Tapsell LC, Gillen LJ, Patch CS, Batterham MJ, Owen A, Bare M, Kennedy M:

Including walnuts in a low-fat/modified-fat diet improves HDL cholesterol-to-total cholesterol ratios in patients with type 2 diabetes. Diab Care 27:2777-83, 2004.

[35] Suhasini GE, Krishna DR: Influence of unrefined sorghum or maize on serum lipids. Anc Sci Life 1\&2:26-7, 1991.

[36] Khan I, Yousif AM, Johnson SK, Gamlath S: Acute effect of sorghum flour-containing pasta on plasma total polyphenols, antioxidant capacity and oxidative stress markers in healthy subjects: A randomised controlled trial. Clin Nutr 34:415-21, 2015.

[37] Sies H: Total Antioxidant Capacity: Appraisal of a Concept. J Nutr 137:1493-95, 2007.

[38] Schembre SM, Yuen J: Project TwEATs. A feasibility study testing the use of automated test messaging to monitor appetite ratings in a free-living population. Appetite 56:465-68, 2011.

[39] Alhassan S, Kim S, Bersamin A, King AC, Gardner CD: Dietary adherence and weight loss success among overweight women: results from the A TO Z weight loss study. Int J Obes (Lond) 32:985-91, 2008.

[40] Desroches S, Lapointe A, Ratté S, Gravel K, Légaré F, Turcotte S: Interventions to enhance adherence to dietary advice for preventing and managing chronic diseases in adults (Review). Cochrane Database Syst Rev 2:CD008722, 2013. 
Table 1 - Dietary prescription (totaling $5,500 \mathrm{~kJ}$ ) for a typical participant

\begin{tabular}{lll} 
Food Group & Portion or serve size & Number of serves / day \\
\hline Control or intervention products & 1 flaked cereal biscuit $=15 \mathrm{~g}$ & 3 (2 biscuits at breakfast and 1 at afternoon tea) \\
Breads/cereal/starchy vegetables & 1 slice bread or $1 / 2$ cup cooked pasta or $1 / 3$ cup cooked rice or 1 small potato & 4 \\
Other vegetables & $1 / 2$ cup cooked or 1 cup raw & 2.5 cooked or 5 raw \\
Fruit & 1 piece fresh or $3 / 4$ cup canned and drained & 2 \\
Milk / alternatives & $150 \mathrm{ml}$ light or $200 \mathrm{ml}$ skim, $100 \mathrm{~g}$ low-fat yoghurt & $2-3$ \\
Meat / alternatives & $30 \mathrm{~g}$ meat or $50 \mathrm{~g}$ fish or $20 \mathrm{~g}$ low fat cheese & $3-4$ \\
Fats & 1 tsp. oil or margarine or 1 tbsp. avocado & $3-4$ \\
\hline
\end{tabular}


Table 2 - Proximate and dietary fiber composition and energy content of flaked breakfast cereals, adapted from Stefoska-Needham et al. (2016) ${ }^{1,2}$

\begin{tabular}{|c|c|c|c|c|c|c|c|}
\hline $\begin{array}{l}\text { Flaked breakfast cereal } \\
\text { type }\end{array}$ & $\begin{array}{l}\text { Moisture } \\
\text { (g/100g as is) }\end{array}$ & $\begin{array}{c}\text { Protein } \\
\text { (g/100g as is) }\end{array}$ & $\begin{array}{c}\text { Fat } \\
(\mathrm{g} / \mathbf{1 0 0 g} \text { as is })\end{array}$ & $\begin{array}{c}\text { Ash }^{3} \\
(\mathrm{~g} / 100 \mathrm{~g} \text { as is })\end{array}$ & 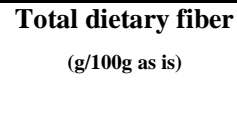 & $\begin{array}{c}\text { Total available } \\
\text { carbohydrates }^{4} \\
(\mathrm{~g} / 100 \mathrm{~g} \text { as is })\end{array}$ & $\begin{array}{c}\text { Energy content } \\
\text { (kJ/100g as is) }\end{array}$ \\
\hline Wheat control & $6.6 \pm 0.0$ & $13.7 \pm 0.2^{\mathrm{b}}$ & $1.7 \pm 0.0^{\mathrm{a}}$ & $1.6 \pm 0.0$ & $9.6 \pm 0.1^{\mathrm{b}}$ & $66.9 \pm 0.1^{\mathrm{a}}$ & $1508 \pm 1^{a}$ \\
\hline Sorghum (red) & $6.6 \pm 0.0$ & $9.4 \pm 0.1^{\mathrm{a}}$ & $2.9 \pm 0.1^{\mathrm{b}}$ & $1.6 \pm 0.0$ & $7.7 \pm 0.0^{\mathrm{a}}$ & $71.9 \pm 0.1^{\mathrm{b}}$ & $1550 \pm 0^{\mathrm{b}}$ \\
\hline
\end{tabular}

${ }^{1}$ Means $(\mathrm{n}=2) \pm$ standard deviation

${ }^{2}$ Values within a column with the same superscript letter denotes no significant difference $(p>0.05)$

${ }^{3}$ Statistical comparison not possible as son

${ }^{4}$ Available carbohydrate calculated by difference 
Table 3 - Free, bound and total phenolic content and antioxidant capacity of flaked breakfast cereals, adapted from Stefoska-Needham et al. (2016) ${ }^{1,2}$

\begin{tabular}{|c|c|c|c|c|c|c|}
\hline $\begin{array}{l}\text { Flaked breakfast cereal } \\
\text { type }\end{array}$ & $\begin{array}{c}\text { Free PP } \\
\text { (mg GAE/g as is) }\end{array}$ & $\begin{array}{c}\text { Bound PP } \\
\text { (mg GAE/g as is) }\end{array}$ & $\begin{array}{c}\text { Total PP } \\
\text { (mg GAE/g as is) }\end{array}$ & $\begin{array}{c}\text { Free AC } \\
(\mu \mathrm{molTE} / \mathrm{g} \text { as is })\end{array}$ & $\begin{array}{c}\text { Bound AC } \\
(\mu \mathrm{molTE} / \mathrm{g} \text { as is })\end{array}$ & $\begin{array}{c}\text { Total antioxidant capacity } \\
(\mu \mathrm{molTE} / \mathrm{g} \text { as is })\end{array}$ \\
\hline Wheat control & $0.71 \pm 0.01^{\mathrm{a}}$ & $0.67 \pm 0.22^{\mathrm{a}}$ & $1.37 \pm 0.21^{\mathrm{a}}$ & $2.64 \pm 0.01^{\mathrm{a}}$ & $2.67 \pm 0.01^{\mathrm{a}}$ & $5.31 \pm 0.01^{\mathrm{a}}$ \\
\hline Sorghum (red) & $1.27 \pm 0.01^{\mathrm{b}}$ & $1.00 \pm 0.11^{\mathrm{a}}$ & $2.27 \pm 0.12^{\mathrm{b}}$ & $11.25 \pm 0.57^{\mathrm{b}}$ & $9.16 \pm 0.62^{b}$ & $20.40 \pm 1.18^{\mathrm{b}}$ \\
\hline
\end{tabular}

${ }^{\mathrm{I}}$ Means $(\mathrm{n}=2) \pm$ standard deviation

${ }^{2}$ Values within a column with the same superscript letter denotes no significant difference $(\mathrm{p}>0.05)$

PP, polyphenolic; AC, antioxidant capacity; GAE, Gallic acid equivalents; TE, Trolox equivalents 
Table 4 - Starch properties of flaked breakfast cereals, adapted from Stefoska-Needham et al. (2016) ${ }^{1,2}$

\begin{tabular}{lcccc}
\hline $\begin{array}{l}\text { Flaked breakfast } \\
\text { cereal type }\end{array}$ & $\begin{array}{c}\text { Total starch } \\
(\mathrm{g} / \mathbf{1 0 0 g} \text { as is })\end{array}$ & $\begin{array}{c}\text { Rapidly digested starch } \\
(\mathrm{g} / \mathbf{1 0 0 g} \text { dry starch })\end{array}$ & $\begin{array}{c}\text { Slowly digested starch } \\
(\mathrm{g} / \mathbf{1 0 0 g} \text { dry starch })\end{array}$ & $\begin{array}{c}\text { Resistant starch } \\
(\mathrm{g} / \mathbf{1 0 0 g} \text { dry starch })\end{array}$ \\
\hline Wheat control & $54.2 \pm 0.2^{\mathrm{a}}$ & $31.9 \pm 1.6^{\mathrm{a}}$ & $47.9 \pm 4.2^{\mathrm{a}}$ & $20.2 \pm 3.9^{\mathrm{a}}$ \\
Sorghum (red) & $57.7 \pm 2.3^{\mathrm{a}}$ & $31.9 \pm 4.2^{\mathrm{a}}$ & $46.9 \pm 7.7^{\mathrm{a}}$ & $21.2 \pm 3.6^{\mathrm{a}}$ \\
\hline
\end{tabular}

${ }^{1}$ Means $(\mathrm{n}=2) \pm$ standard deviation

${ }^{2}$ Values within a column with the same superscript letter denotes no significant difference ( $\left.\mathrm{p}>0.05\right)$

${ }^{3}$ Total starch was determined using a Megazyme K-TSTA 09/14 Total Starch Kit (Bray, Ireland) which excludes low molecular weight starch

hydrolysis/breakdown products that may have resulted during the manufacturing process 
Table 5 - Baseline characteristics of study subjects (means and standard deviations)

\begin{tabular}{|c|c|c|c|c|c|}
\hline \multirow{2}{*}{ VARIABLE } & \multicolumn{2}{|c|}{ CONTROL } & \multicolumn{2}{|c|}{ SORGHUM } & \multirow{2}{*}{$\begin{array}{c}\text { DIFFERENCE } \\
p \text {-value }\end{array}$} \\
\hline & Mean & $S D$ & Mean & $S D$ & \\
\hline Age (years) & 48.6 & 11.4 & 48.1 & 10.3 & 0.859 \\
\hline Weight (kg) & 86.1 & 9.8 & 87.1 & 12.9 & 0.732 \\
\hline $\operatorname{BMI}\left(\mathrm{kg} / \mathrm{m}^{2}\right)$ & 31.6 & 2.8 & 31.2 & 3.5 & 0.632 \\
\hline Waist $(\mathrm{cm})$ & 105.3 & 9.5 & 102.5 & 12.0 & 0.311 \\
\hline Fat $(\%)$ & 40.3 & 5.8 & 38.7 & 6.3 & 0.309 \\
\hline Fasting Blood glucose $(\mathrm{mmol} / \mathrm{L})$ & 5.2 & 0.4 & 5.3 & 0.6 & 0.297 \\
\hline Fasting Insulin (mIU/L) & 12.5 & 5.7 & 12.3 & 6.9 & 0.893 \\
\hline $\operatorname{HbA1c}(\%)$ & 5.3 & 0.3 & 5.2 & 0.4 & 0.554 \\
\hline Total Cholesterol (mmol/L) & 5.6 & 1.0 & 5.3 & 1.0 & 0.173 \\
\hline LDL-c $(\mathrm{mmol} / \mathrm{L})$ & 3.5 & 0.9 & 3.2 & 0.8 & 0.193 \\
\hline HDL-c (mmol/L) & 1.4 & 0.4 & 1.5 & 0.3 & 0.533 \\
\hline $\mathrm{TAG}(\mathrm{mmol} / \mathrm{L})$ & 1.6 & 0.8 & 1.3 & 0.7 & 0.155 \\
\hline $\operatorname{IL} 1 \beta(\mathrm{pg} / \mathrm{ml})$ & 0.9 & 1.0 & 0.9 & 0.9 & 0.841 \\
\hline $\mathrm{Il}-6(\mathrm{pg} / \mathrm{ml})$ & 1.5 & 1.6 & 0.8 & 0.7 & 0.052 \\
\hline $\mathrm{Il}-8(\mathrm{pg} / \mathrm{ml})$ & 6.2 & 2.8 & 5.2 & 1.8 & 0.096 \\
\hline $\mathrm{TNF} \alpha(\mathrm{pg} / \mathrm{ml})$ & 2.9 & 1.3 & 3.2 & 1.2 & 0.483 \\
\hline $\mathrm{hsCRP}(\mathrm{mg} / \mathrm{L})$ & 2.7 & 2.6 & 2.4 & 2.1 & 0.662 \\
\hline TAC (mmol/L Trolox) & 1.2 & 0.2 & 1.3 & 0.2 & 0.476 \\
\hline Diastolic BP (mm Hg) & 82.3 & 9.6 & 80.4 & 7.4 & 0.407 \\
\hline Systolic BP (mm Hg) & 126.2 & 16.9 & 122.3 & 14.4 & 0.349 \\
\hline
\end{tabular}


Table 6 - Energy and macronutrient intakes reported by subjects at baseline, mid-point and 3-months, with p-values for repeated measures ANOVA between control and sorghum groups (mean values and standard deviations)

\begin{tabular}{|c|c|c|c|c|c|c|c|c|c|c|c|c|c|c|c|}
\hline \multirow[b]{3}{*}{ VARIABLE } & \multicolumn{4}{|c|}{ BASELINE } & \multicolumn{4}{|c|}{ MID-POINT } & \multicolumn{4}{|c|}{3 MONTHS } & \multicolumn{3}{|c|}{ P-VALUES } \\
\hline & \multicolumn{2}{|c|}{ CONTROL } & \multicolumn{2}{|c|}{ SORGHUM } & \multicolumn{2}{|c|}{ CONTROL } & \multicolumn{2}{|c|}{ SORGHUM } & \multicolumn{2}{|c|}{ CONTROL } & \multicolumn{2}{|c|}{ SORGHUM } & \multirow{2}{*}{ Group } & \multirow[b]{2}{*}{ Time } & \multirow[b]{2}{*}{ Interaction } \\
\hline & Mean & $S D$ & Mean & $S D$ & Mean & $S D$ & Mean & $S D$ & Mean & $S D$ & Mean & $S D$ & & & \\
\hline Energy $(\mathrm{kJ})$ & 9274.0 & 2696.2 & 7897.3 & 2429.8 & 6993.0 & 2244.8 & 7363.9 & 2076.2 & 6752.8 & 2090.6 & 7082.0 & 1297.1 & 0.110 & $<0.001 *$ & 0.671 \\
\hline Protein (g) & 106.6 & 33.2 & 89.5 & 30.8 & 88.9 & 35.0 & 95.4 & 32.6 & 81.7 & 26.2 & 89.6 & 24.7 & $0.049 *$ & $0.008 *$ & 0.909 \\
\hline$\%$ E Protein & 20.0 & 5.2 & 19.5 & 4.1 & 22.4 & 6.5 & 21.9 & 4.0 & 20.7 & 3.4 & 21.5 & 4.1 & 0.56 & 0.059 & \\
\hline $\mathrm{CHO}(\mathrm{g})$ & 234.6 & 84.5 & 190.6 & 60.7 & 187.8 & 74.4 & 181.4 & 43.5 & 177.9 & 56.8 & 183.2 & 40.9 & 0.144 & $0.040^{*}$ & 0.306 \\
\hline$\% \mathrm{E} \mathrm{CHO}$ & 39.9 & 5.1 & 39.1 & 7.09 & 42.6 & 8.3 & 40.0 & 5.2 & 42.6 & 6.3 & 41.5 & 6.0 & 0.811 & 0.161 & \\
\hline Total Fat (g) & 85.1 & 25.7 & 77.2 & 31.5 & 54.9 & 23.5 & 61.9 & 26.0 & 57.1 & 23.8 & 57.6 & 15.3 & $<0.001^{*}$ & 0.381 & 0.979 \\
\hline$\%$ E Total Fat & 34.0 & 5.2 & 35.5 & 5.3 & 28.5 & 5.4 & 30.4 & 4.9 & 30.8 & 7.0 & 30.1 & 5.2 & 0.435 & $<0.001 *$ & \\
\hline SFA (g) & 34.3 & 12.4 & 29.8 & 14.3 & 18.4 & 7.4 & 22.9 & 10.9 & 20.3 & 8.6 & 20.4 & 5.8 & 0.161 & $<0.001 *$ & 0.976 \\
\hline$\%$ E SFA & 13.7 & 3.2 & 13.6 & 3.3 & 9.7 & 2.0 & 11.3 & 2.8 & 11.0 & 3.0 & 10.7 & 2.2 & 0.090 & $<0.001 *$ & \\
\hline PUFA (g) & 12.7 & 5.3 & 12.9 & 6.6 & 9.7 & 5.8 & 9.3 & 5.0 & 9.1 & 4.7 & 9.5 & 4.2 & 0.829 & $0.003^{*}$ & 0.946 \\
\hline$\%$ E PUFA & 5.1 & 1.7 & 6.1 & 2.8 & 4.9 & 2.0 & 4.5 & 1.5 & 4.9 & 1.9 & 4.9 & 1.6 & 0.234 & 0.081 & \\
\hline MUFA (g) & 31.6 & 10.8 & 28.8 & 14.2 & 20.3 & 10.5 & 23.0 & 11.0 & 21.3 & 6.5 & 21.5 & 6.5 & 0.486 & $<0.001^{*}$ & 0.970 \\
\hline$\%$ E MUFA & 12.6 & 2.8 & 13.1 & 3.2 & 10.4 & 3.2 & 11.2 & 2.6 & 11.3 & 4.0 & 11.3 & 2.8 & 0.789 & $0.005^{*}$ & \\
\hline Total Fiber (g) & 26.3 & 9.0 & 25.6 & 9.5 & 24.4 & 9.1 & 24.9 & 7.2 & 24.1 & 9.2 & 27.2 & 10.2 & 0.432 & 0.626 & 0.660 \\
\hline
\end{tabular}

E - energy; CHO - carbohydrate

* Significant values $(\mathrm{p}<0.05)$ were measured using repeated measures ANOVA 
Table 7 - Changes in anthropometric and biochemical indices over time between control and sorghum groups (mean values and standard deviations)

\begin{tabular}{|c|c|c|c|c|c|c|c|c|c|c|c|c|c|c|c|}
\hline \multirow{3}{*}{$\begin{array}{l}\text { CLINICAL } \\
\text { INDICES }\end{array}$} & \multicolumn{4}{|c|}{ ALL GROUPS } & \multicolumn{4}{|c|}{ CONTROL } & \multicolumn{4}{|c|}{ SORGHUM } & \multirow{2}{*}{\multicolumn{3}{|c|}{ P-VALUES }} \\
\hline & \multicolumn{2}{|c|}{ Baseline data } & \multicolumn{2}{|c|}{ Mean change } & \multicolumn{2}{|c|}{ Baseline data } & \multicolumn{2}{|c|}{ Mean change } & \multicolumn{2}{|c|}{ Baseline data } & \multicolumn{2}{|c|}{ Mean change } & & & \\
\hline & Mean & $S D$ & Mean & $S D$ & Mean & $S D$ & Mean & $S D$ & Mean & $S D$ & Mean & $S D$ & Group & Time & Interaction \\
\hline Weight (kg) & 86.6 & 11.6 & -5.3 & 3.7 & 86.1 & 9.8 & -5.4 & 3.6 & 87.1 & 13.6 & -5.2 & 4.0 & 0.369 & $<0.001 *$ & 0.772 \\
\hline BMI $\left(\mathrm{kg} / \mathrm{m}^{2}\right)$ & 31.3 & 3.1 & -1.9 & 1.4 & 31.6 & 2.6 & -1.9 & 1.3 & 31.1 & 3.4 & -1.9 & 1.4 & 0.754 & $<0.001 *$ & 0.601 \\
\hline Waist (cm) & 104.2 & 10.9 & -10.9 & 5.4 & 105.3 & 9.5 & -11.8 & 5.6 & 102.9 & 12.5 & -9.9 & 5.2 & 0.209 & $<0.001 *$ & 0.594 \\
\hline Body fat (\%) & 39.4 & 6.0 & -2.1 & 2.3 & 40.3 & 5.8 & -2.1 & 2.3 & 38.3 & 6.9 & -2.3 & 2.5 & 0.876 & $<0.001 *$ & 0.194 \\
\hline Glucose $(\mathrm{mmol} / \mathrm{L})$ & 5.26 & 0.50 & -0.13 & 0.4 & 5.18 & 0.36 & -0.11 & 0.3 & 5.35 & 0.62 & -0.15 & 0.4 & 0.705 & $0.009^{*}$ & 0.162 \\
\hline Insulin (mIU/L) & 12.32 & 5.78 & -2.86 & 3.3 & 12.55 & 5.8 & -3.17 & 3.0 & 12.06 & 5.86 & -2.53 & 3.7 & 0.481 & $0.000^{*}$ & 0.905 \\
\hline $\mathrm{HbA1c}(\mathrm{mmol} / \mathrm{L})$ & 33.95 & 4.2 & 0.10 & 3.1 & 33.97 & 3.89 & 0.20 & 3.2 & 33.92 & 4.60 & 0.00 & 2.9 & 0.843 & 0.843 & 0.896 \\
\hline $\mathrm{HbA1c}(\%)$ & 5.26 & 0.37 & 0.00 & 0.3 & 5.26 & 0.34 & 0.00 & 0.3 & 5.25 & 0.41 & 0.00 & 0.2 & 0.926 & 0.926 & 0.912 \\
\hline $\begin{array}{l}\text { Total cholesterol } \\
(\mathrm{mmol} / \mathrm{L})\end{array}$ & 5.47 & 0.99 & -0.40 & 0.7 & 5.64 & 0.98 & -0.50 & 0.7 & 5.28 & 0.99 & -0.30 & 0.6 & 0.139 & $<0.001 *$ & 0.384 \\
\hline HDL-c (mmol/L) & 1.42 & 0.38 & -0.07 & 0.2 & 1.40 & 0.40 & -0.10 & 0.2 & 1.45 & 0.37 & -0.10 & 0.2 & 0.674 & $0.008^{*}$ & 0.454 \\
\hline LDL-c (mmol/L) & 3.39 & 0.85 & -0.15 & 0.5 & 3.52 & 0.90 & -0.20 & 0.6 & 3.24 & 0.79 & -0.10 & 0.4 & 0.225 & 0.05 & 0.379 \\
\hline TAG (mmol/L) & 1.46 & 0.76 & -0.40 & 0.6 & 1.59 & 0.81 & -0.50 & 0.7 & 1.30 & 0.67 & -0.30 & 0.5 & 0.393 & $<0.001 *$ & 0.174 \\
\hline $\operatorname{IL} 1 \beta(\mathrm{pg} / \mathrm{ml})$ & 0.93 & 0.97 & -0.15 & 0.4 & 0.92 & 1.03 & -0.10 & 0.4 & 0.94 & 0.92 & -0.20 & 0.3 & 0.565 & 0.004* & 0.943 \\
\hline Il-6 (pg/ml) & 1.19 & 1.29 & -0.22 & 0.3 & 1.48 & 1.59 & -0.20 & 0.4 & 0.86 & 0.73 & -0.20 & 0.3 & 0.752 & $<0.001 *$ & 0.071 \\
\hline IL-8 (pg/ml) & 5.73 & 2.46 & -0.49 & 1.1 & 6.20 & 2.84 & -0.40 & 1.2 & 5.19 & 1.86 & -0.60 & 0.9 & 0.621 & $0.001 *$ & 0.075 \\
\hline hsCRP (mg/L) & 2.52 & 2.41 & -0.28 & 1.8 & 2.65 & 2.64 & -0.30 & 2.1 & 2.37 & 2.15 & -0.20 & 1.3 & 0.059 & 0.207 & 0.728 \\
\hline $\mathrm{TNF} \alpha(\mathrm{pg} / \mathrm{ml})$ & 3.06 & 1.23 & -0.76 & 0.8 & 2.95 & 1.27 & -0.60 & 0.7 & 3.19 & 1.18 & -0.90 & 0.8 & 0.110 & $<0.001 *$ & 0.748 \\
\hline $\begin{array}{l}\text { TAC (mmol/L } \\
\text { Trolox) }\end{array}$ & 1.26 & 0.18 & -0.06 & 0.1 & 1.24 & 0.15 & -0.10 & 0.1 & 1.29 & 0.20 & -0.10 & 0.1 & 0.759 & $0.001 *$ & 0.247 \\
\hline
\end{tabular}

$\mathrm{c}$ - cholesterol; TAG - triacylglycerides; HbA1c - glycosylated hemoglobin; IL1 $\beta$ - Interleukin 1 $\beta$; Il-6 - Interleukin 6; IL-8 - Interleukin 8; hsCRP - high sensitivity c-reactive protein; TNF $\alpha$ - tumour necrosis factor alpha; TAC - total antioxidant capacity

* Significant values were measured using repeated measures ANOVA 


\section{Fig. 1 Flow of participants through the trial}

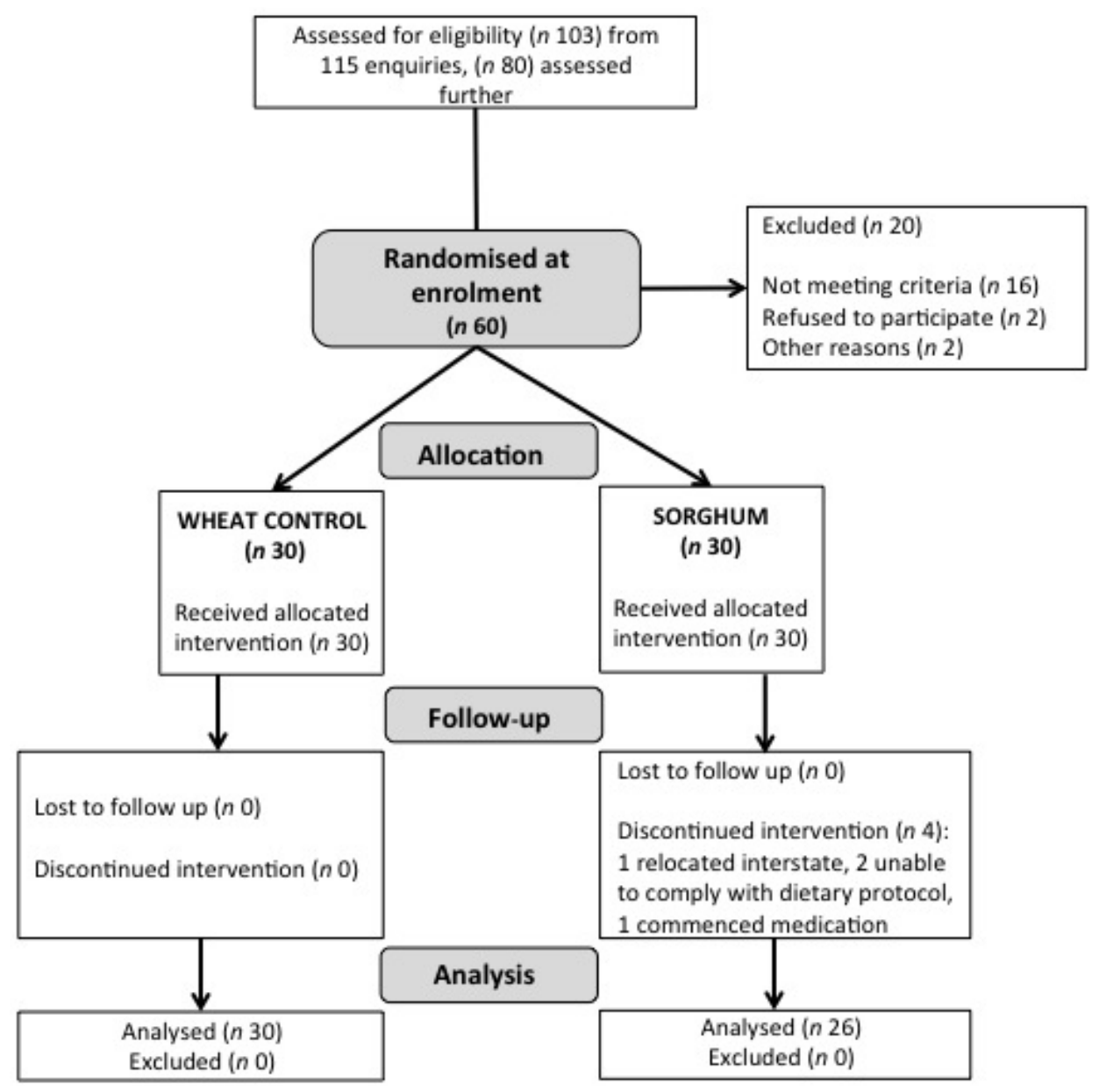

